\title{
Comparing the Effects of Defaults in Organ Donation Systems
}

\author{
Hendrik P. van Dalen ${ }^{1,2}$ and Kène Henkens ${ }^{1,3,4}$
}

Version: December 24, 2013

(1) Netherlands Interdisciplinary Demographic Institute (NIDI)

P.O. Box 11650

NL-2502 AR The Hague

The Netherlands

Email: dalen@ nidi.nl

(2) Tilburg University

Tilburg School of Economics and Management (TISEM) and CentER

P.O. Box 90153

NL-5000 LE Tilburg

The Netherlands

(3) University of Amsterdam

Department of Anthropology and Sociology

Oudezijds Achterburgwal 185

NL-1012 DK Amsterdam

The Netherlands

(4) University of Groningen

UMCG

P.O. Box 72

NL-9700 AB Groningen

The Netherlands

This is a post-print version of the article which has appeared in Social Science and Medicine,

volume106, see: http://www.sciencedirect.com/science/article/pii/S0277953614000938

Please cite this paper as:

H.P. van Dalen, and K. Henkens, 2014, Comparing the Effects of Defaults in Organ Donation Systems, Social Science and Medicine, 106: 137-142. 


\begin{abstract}
The ability of patients in many parts of the world to benefit from transplantation is limited by growing shortages of transplantable organs. The choice architecture of donation systems is said to play a pivotal role in explaining this gap. In this paper we examine the question how different defaults affect the decision to register as organ donor. Three defaults in organ donation systems are compared: mandated choice, presumed consent and explicit consent. Hypothetical choices from a national survey of 2,069 respondents in the Netherlands - a country with an explicit consent system - suggests that mandated choice and presumed consent are more effective at generating registered donors than explicit consent.
\end{abstract}

\title{
Keywords:
}

Organ donation

Behavioural economics

Mandatory choice

Defaults

Netherlands 


\section{Introduction}

Throughout the developed world one of the most pressing health problems is a persistent shortage for transplantable organs. The discrepancy between demand and supply results in long waiting times for patients who are in need of an organ (British Medical Association, 2012; Howard, 2007; Johnson \& Goldstein, 2003). The policy debate in many countries revolves around solving this shortage. To shed light and inform this debate this paper exams how different systems of organ donation registration affect individual choice. The main debate seems to focus on the two most dominant systems: the explicit consent versus the presumed consent system. In the explicit consent system, the default is that nobody is a donor, and in order to become one they have to officially register ('opt in') their status as organ donor. The drawback of relying on such a spontaneous form of altruism is that due to procrastination or inertia the donation rate can be quite low and less than the willingness to donate. Some of these drawbacks are resolved in a presumed consent system. In such a system every adult citizen is by default a donor, unless they choose to opt out of this system. Johnson and Goldstein (2003) used a US sample to show how a presumed consent system in which people may 'opt out' generates a substantially higher percentage of registered donors than a system which explicitly makes people state their consent to donate their organs in case they die.

One of the drawbacks of the presumed consent system is that families of a deceased relative may object and withdraw the presumed consent. Furthermore, government can be seen as taking advantage of the inertia or inattention of citizens in giving consent. Spital $(1995,1996)$ was one of the first to suggest a way out of this dilemma: mandated choice. By forcing people to make a choice one can mitigate the ethical drawbacks of the presumed consent system, but it remains uncertain whether this will lead to substantial higher donation 
rates. Even clearly framed questions cannot prevent the possibility that people are uncertain and leave room for revoking an earlier made decision. In this paper we provide a replication and extension of the widely cited study of Johnson and Goldstein (2003) and measure whether there are substantial differences across three alternative donation systems. We use a survey among the Dutch population of which 48 percent of the respondents say they are registered organ donors. The Netherlands is a country which has an explicit consent system and like many other countries has to solve the problem of too few organ donors (Coppen et al. 2008).

\section{Setting defaults in organ donation}

It is well-established that defaults matter in individual choice (cf. Abadie \& Gay, 2006; Choi et al., 2003; Dinner et al., 2011; Johnson \& Goldstein 2003; Kahneman, 2003; Keller et al., 2011; Thaler et al., 2010) and organ donation is no exception to this rule. The basic reason why defaults generate such a large effect is that people, contrary to what neoclassical economists would assume, do not have explicit preferences with respect to every imaginable good or service. It would be more appropriate to assume that people specifically in the case of organ donation still have to form preferences. Under such circumstances the framing and setup of donation systems can be of crucial importance. Governments may be giving 'nudges' towards citizens by the setting of defaults of what may be an optimal standard for the average citizen (see Thaler \& Sunstein, 2009). For those who are inert in forming preferences the default will offer solace in resolving their choice problem. Another reason why defaults exert such a large influence is that people often display loss aversion in making choices. Moving away from the default involves losses and gains, and those losses typically receive disproportionate weight which makes people stick to the status quo or default option. 
Besides the presumed and explicit consent system a third option has gained some popularity in policy debates, i.e. mandated choice. Evidence on the effects of a mandated choice system is limited. Only New Zealand has since the 1980 s a system a mandated choice system in which registration is only possible via the driver's license (see Rosenblum et al., 2012). Hence the system excludes all non-drivers, including those under age 15 to register as donor. Besides the New Zealand practice only a few experiments of recent date exist. From 1 August 2011British citizens who wish to apply for a new, or renewed, driving license online have been required to answer a question about organ donation (British Medical Association, 2012). A similar system has been used in a number of US states. E.g., in the 1990s licensed drivers in Texas were required to state their views about donation before obtaining a license (Klassen \& Klassen, 1996; Siminoff \& Mercer, 2001). However, the experience of Texas has been disappointing and has led the state to abandon this system. New experiments in some states (such as Illinois) with an alternative design seem to be promising (Thaler et al., 2010). Overall, the limited experience with mandated choice is mixed and suggests that it is not clear a priori whether a mandated choice yields more registered donors than the prevailing systems of donation. The debate about donation system is in need of empirical answers of what works and of gaining insight into how people choose across different systems within one country.

\section{Method}

\section{Sample}

In May 2011 we administered a survey among the Dutch population of age 16 and older $(\mathrm{N}=$ 2,069 and response rate 77 percent). The survey was conducted by the CentERdata, a survey institute of Tilburg University (for details, see http://www.centerdata.nl/en/) that maintains a large panel of households in the Netherlands. The inclusion of immigrants in this panel is weak and because immigrants are known for having far lower donation rates than native born 
the presented donation rates in this survey may not apply to the entire population. However, for the purpose at hand - comparing donation rates under various institutional regimes and understanding the underlying forces - the survey is well attuned. Furthermore, we carried out a t-test to see whether the donor question referring to the explicit consent regime (which is the Dutch system) is in line with the actual (self-reported) donor registration rates. As it turned out the mean difference between the two donation rates (respectively $49.6 \%$ and $48.4 \%)$ is not different from zero ( $\mathrm{p}$-value $=0.64)$.

\section{Donor systems compared}

To test for differences in choices across donation systems, the sample was divided into four different groups A, B, C and D of equal size and assignment to the groups was random. In total four systems or donation regimes were compared: an explicit consent system $(\mathrm{N}=$ 466); the presumed consent system $(\mathrm{N}=513)$; the system in which the donor choice is mandatory $(\mathrm{N}=528)$; and finally a neutral system was presented in which respondents were asked whether they would be willing to become an organ donor $(\mathrm{N}=562)$. For the entire sample we also asked whether respondents are officially registered as an organ donor. The latter question is used as a benchmark to study in depth the way actual donor choices are in line with donation behavior across donor systems. The various donor systems are introduced to the respondents by asking a different question to each of the four subgroups. Respondents of each group were told in the introduction to the question that it is assumed that each state or province within the Netherlands has the right to decide upon their own system of donation.

\section{Explicit consent}

Group A had to make a choice in an explicit consent system (also known as 'opt in'-system). Respondents were asked "Suppose you move to another province where the donor system is 
such that you are not automatically an organ donor. You have to explicitly register as a donor. What would you do?" The answer options were (a) I will leave it as it is and not become a donor; (b) I will register as a donor; and (c) Don't know.

\section{Presumed consent}

Group B dealt with the case of the presumed consent system (also known as an 'opt out'system). Respondents were asked: "Suppose you move to another province where the system is such that you are automatically a donor, unless you explicitly object. What would you do?" The answer options were (a) I will leave it as it is and become automatically a donor; (b) I will object and will not become a donor; and (c) Don't know.

\section{Mandated choice}

Group C faced the mandated choice system. This system was introduced to respondents as follows: "Suppose that every time you have to renew your passport at the local municipality you are also obliged to make a choice with respect to organ donation. In case you will renew your passport in the coming week what will be your response with respect to the question 'Do you want to be an organ donor?"' The simple answer options were (a) Yes, and (b) No.

\section{Willingness to become organ donor}

Finally, group D was asked the neutral question “Are you willing to become an organ donor?" The answer options were (a) Yes, I want to become a donor and; (b) No, I don't want to become a donor; and (c) I don't know and I will delegate this decision to my relatives. The neutrality stems from the fact that no institutional detail is provided by terms of defaults. However, one could also interpret this question as a 'softer' version of the mandated choice setting where the decision maker can opt to have the next-of-kin decide. 


\section{Results}

Comparing donor systems

The respective hypothetical choices (in percentages) are depicted in Figure 1. A number of observations are noteworthy. First, based on donation rates in an explicit consent system (50 percent) a reform in the direction of a presumed consent system would be an improvement as the number of registered donors increases by approximately 12 percentage points, reaching a donation rate of 62 percent. Second, the system with a mandated choice also results in a substantial increase in the number of donors: 66 percent of the respondents agrees to become a donor. And based on the preferences of people in group D who express their willingness to become a donor, the explicit system apparently generates too few donors as 57 percent is willing to donate their organ. If one takes the status quo (explicit consent) as the benchmark than all alternatives offer a significant increase in donors $(p<0.01)$.

\section{HERE FIGURE 1}

\section{Uncertain preferences}

Another point to notice in Figure 1 is the fact that there is a substantial percentage of respondents who do not have clear preferences. A more refined verdict on the various systems depends therefore on how one treats these categories. E.g., if those respondents who don't know which option to choose are allocated to the default setting the gap in donation registration rates between a presumed and explicit consent system widens. In the case of explicit consent the percentage of registered donors remains $50 \%$, but in case of presumed consent the donation rate becomes $82 \%$. Figure 2 sheds some light on the question how 
answers differ across the various regimes for those who report being currently registered as a donor and those who report not being a donor.

\section{HERE FIGURE 2}

Those who are a registered organ donor are in approximately 90 percent of the cases also a donor in the various regimes. This suggests that those who are donor do not radically change their mind in a different donor regime. For those who are not a registered donor the percentages differ quite substantially across the donor regimes. The donation rate for this group is far higher under a presumed consent and mandatory choice regime (37\%, resp. $39 \%)$ than under explicit consent $(10 \%)$ or in a neutral setting (20\%). This underscores the potential of switching regimes in increasing the number of donors among those who are currently not registered as donor.

\section{Multivariate analysis}

In trying to understand the power of default settings in more detail Table 1 presents the multivariate analysis of the choice to register as a donor. Column I offers the results for the pooled sample of hypothetical choices across donor regimes A-D. And to see how these choices differ by controlling for social-demographic characteristics and the stated donor registration status, column II is presented.

The statistical differences across the four donor regimes are quite clearly presented in column I with the explicit consent system as the benchmark. The probability of donation increases substantially across all regimes, with the system of mandated choice offering the largest increase in probability: the odds of registering as a donor when prompted to choose are 2.03 times larger than in the case of an explicit consent system. 
Column II adds more depth to the analysis by relating choices to a number of socialdemographic characteristics and controlling for the stated donor registration. A number of points should be noted. The health status and the level education exert a positive effect on the chance of registering as a donor, whereas religion exerts the largest and negative effect on donor choice.

\section{HERE TABLE 1}

However, the most prominent effects to be noted are the changes in the odds ratios for the various donor regimes. The odds to become a donor compared to the explicit consent regime increase substantially across all alternative regimes. The higher coefficients for donor regimes B-D (compared to column I) and the strong correlation with registered donor status suggests that most of the effects generated by the donor regimes is to change the minds of those who have not registered or who don't know whether they are registered.

\section{Discussion}

How can a country raise the number of registered organ donors? That is the question at the forefront of health policy debates (cf. British Medical Association 2012; Spital, 1996; Siminoff \& Mercer, 2001; Whyte et al., 2012). The contribution of behavioural sciences is to show that designing a better choice architecture of organ donation systems can potentially generate substantial welfare gains as it will be able to save lives of people who are waiting for a suitable transplant organ. For the case of the Netherlands - a country with an explicit consent system - we show that both a system of mandated choice and a system of presumed consent are more effective in increasing the number of registered donors than an explicit consent system. 
Three issues merit some discussion in interpreting and possibly applying these results. The first concerns the reason why people - when prompted to make a decision - are more prone to donate their organs - as in the mandated choice system - than when they have to make a voluntary explicit choice, as would be the case in an explicit consent regime. This may be related to the propensity to procrastinate which is a common element in making choices as a way of dealing with fear and anxiety (Luce, 1998). Because people are overly optimistic that when they have more time they will make more informed and better decisions (Zauberman \& Lynch, 2005), they are inclined to delay a potential positive decision about becoming a donor in explicit consent system. Another reason why mandated choice may generate more donors may be tied to the context or meaning in which choices are made (cf. Whyte et al., 2012). For instance, the context in which we have positioned the mandated choice is the choice connected to the request of a passport. Such a request is an act which every Dutch citizen is obliged to make and passports have to be renewed every five years. Thereby the donation may be perceived as a temporary implicit contract. This aspect may have given the mandated choice an edge over the explicit consent system, a context in which donation choices may be perceived as a permanent contract (even though the Dutch donor register allows people to revoke or change their donation at any moment in time). An interesting issue for future research is the impact of the duration of donor registration in systems of mandated choice.

A second issue which needs to be further scrutinized is the manner by which default options influence the meaning that people assign to the act of being a donor. Under an explicit consent regime people the act of donation can be seen as an altruistic act and hence the level of solidarity may be stronger than, e.g., a presumed consent system. Davidai et al. (2013) show that in a comparison of the explicit consent and the presumed consent systems, participants in the explicit consent system assign a higher value to the act of being a donor. 
This may enhance commitment later on when the registered donor dies. At such a moment it helps if relatives are aware of this decision and the value which the donor placed on donating his or her organs. However, Davidai et al. did not evaluate the meaning which people attach to a mandated choice. Research by Stutzer et al. (2011) sheds some light on the issue. By means of an experiment for the case of blood donation they show why active choice can induce pro-social behavior, i.e. behavior contributing to a common good. The challenge which donor organizations face is to entice the ignorant or uninformed to think about becoming a donor. And engaging uninformed individuals into an active choice induces them to reflect and form a subjective value of the pro-social activity. Whether this also applies to organ donation was not considered, but the evidence for blood donation shows that active choice substantially increases donations for those subjects who had not reflected on the importance of donating blood before. By contrast, those subjects who had previously reflected on donating blood did not change their contribution.

A third issue concerns the matter of introducing incentives in donation systems, e.g. by 'rewarding' people for making their donation by moving them up the waiting list in case they are in need of donor organs. The new Organ Transplantation Law in Israel suggests that positive effects can be expected. The Israeli reform grants prioritization in organ allocation to candidates who are registered donors and so far this seems to have led to a marked increase in registered donors (Lavee et al. 2013). What makes this reform difficult to evaluate is the fact that the reform also covers other measures - banning reimbursement of transplant tourism involving organ trade and the removal of disincentives for living donation - and the empirical question remains how large these elements of the reform package proved to be in stimulating donation rates. Findings based on a laboratory study by Kessler and Roth (2012) show that a priority system as implemented in Israel could significantly increase the number of donor registrations. However, one should be careful in translating these findings into actual 
practice. First of all, Kessler and Roth (2013) show in a more recent paper that the possibility of loopholes in such systems could backfire and lead to fewer donations once the news is out that the pool of donors is 'poisoned'. A loophole exists when an individual can register to receive priority, but avoid ever being in a position to donate his or her own organs. Such opportunistic individuals could, e.g., instruct their next of kin to prevent donation of their organs upon death. Furthermore, it is well known that making organ donation a market transaction is constrained by concerns about morality and the ethical nature of such practices. Outright repugnance by the general public towards the use of monetary incentives in case of organ donation will limit the feasibility of those initiatives (Leider \& Roth, 2010; Schweda \& Schicktanz, 2009) and the mentioning of incentives may even backfire on governments proposing the option (Whyte et al., 2012).

Finally, there is the issue whether these results are generalizable beyond the country boundaries of the Netherlands. Mocan and Tekin (2007) show that the willingness to donate organs and the antecedents of registered donors in Europe and the US are quite similar. This suggests that issues raised in this study are of some relevance to other western countries. Whether our results apply to non-western countries or immigrants from non-western countries is far more difficult to say.

The value added of the current study is that it controls for country specific preferences and behaviours that might influence the propensities to become a donor across a number of donor systems. But above all, this study gives a more nuanced account of what defaults can achieve by multiple framings of mandated choice and comparing it to actual (self-reported) donor registration choices. Presumed consent and mandated choice are more effective in generating registered donors than a system of explicit consent. However, a clear ranking of mandated and presumed consent systems cannot be made, unless one assigns people with uncertain preferences to the default option. 


\section{References:}

Abadie, A., \& Gay S. (2006). The impact of presumed consent legislation on cadaveric organ donation: A cross-country study. Journal of Health Economics 25(4), 599-620.

British Medical Association (BMA) (2012). Building on progress: Where next for organ donation policy in the UK? London: BMA.

Choi, J.J., Laibson, D., Madrian, B.C., \& Metrick, A. (2003). Optimal defaults, American Economic Review 93(2), 180-185.

Conesa, C., Rios, A., Rodriguez, M.M., Rivas, P., Canteras M., \& Parilla, P. (2003).

Psychosocial profile in favor of organ donation. Transplantation Proceedings 35, 1276-1281.

Coppen, R., Friele, R.D., Gevers, S.K.M., Blok, G.A., \& Van der Zee, J. (2008). The impact of donor policies in Europe: a steady increase, but not everywhere, BMC Health Services Research 8, 235-245.

Davidai, S., Gilovich, T., \& Ross, L.D. (2013). The meaning of default options for potential organ donors, Proceedings of the National Academy of Sciences 109(38), 1520115205.

Dinner, I., Johnson, E.J., Goldstein, D.G., \& Liu, K. (2011). Partitioning default effects: why people choose not to choose, Journal of Experimental Psychology: Applied 17(4), $332-341$.

Howard, D.H. (2007). Producing organ donors. Journal of Economic Perspectives 21, 25-36. 
Johnson, E.J., \& Goldstein, D. (2003). Do defaults save lives? Science, 302, 1338-1339.

Kahneman, D. (2003). Maps of bounded rationality: Psychology for behavioral economics. American Economic Review 93(5), 1449-1475.

Keller, P.A., Harlam, B., Loewenstein, G., \& Volpp, K.G. (2011). Enhanced active choice: A new method to motivate behavior change. Journal of Consumer Psychology 21, 376383.

Kessler, J.B., \& Roth, A.E. (2012). Organ allocation policy and the decision to donate. American Economic Review 102(5), 2018-2047.

Kessler, J. B., \& Roth, A. E. (2013) Organ donation loopholes undermine warm glow giving: An experiment motivated by priority loopholes in Israel, working paper, Philadelphia: University of Pennsylvania.

Klassen, A.C., \& Klassen, D.K. (1996). Who are the donors in organ donation? The family's perspective in mandated choice. Annals of Internal Medicine 125(1), 70-73.

Lavee, J., et al. (2013). Preliminary marked increase in the national organ donation rate in Israel following implementation of a new organ transplantation law. American Journal of Transplantation, 13, 780-785.

Leider, S., \& Roth, A.E. (2010). Kidneys for sale: Who disapproves, and why? American Journal of Transplantation 10(5), 1221-1227.

Luce, M.F. (1998). Choosing to avoid: Coping with negatively emotion-laden consumer decisions. Journal of Consumer Research 24, 409-433. 
Mocan, N., \& Tekin, E. (2007). The determinants of the willingness to donate an organ among young adults: Evidence from the United States and the European Union. Social Science \& Medicine 65, 2527-2538.

NIDI (2011). Defaults in organ donation systems (in Dutch), Survey data collected by CentERdata, May 2011, Tilburg University.

Rosenblum, A.M., et al. (2012). Worldwide variability in deceased organ donation registries, Transplant International 25, 801-811.

Schweda, M., \& Schicktanz, S. (2009). Public ideas and values concerning commercialization of organ donation in four European countries. Social Science \& Medicine 68, 1129-1136.

Siminoff, L.A., \& Mercer, M.B. (2001). Public policy, public opinion, and consent for organ donation. Cambridge Quarterly of Healthcare Ethics 10, 377-386.

Spital, A. (1995). Mandated choice: A plan to increase public commitment to organ donation. Journal of the American Medical Association 273(6), 504-506

Spital, A. (1996). Mandated choice for organ donation: Time to give it a try. Annals of Internal Medicine, 125(1), 66-69.

Stutzer, A., Goette, L., \& Zehnder, M. (2011). Active decisions and prosocial behaviour: A field experiment on blood donation. Economic Journal 121, F476-F493.

Thaler, R.H., \& Sunstein, C.R. (2009). Nudge - Improving decisions about health, wealth and happiness. London: Penguin Books.

Thaler, R.H., Sunstein, C.R., \& Balz, J.P. (2010). Choice architecture. Working paper, University of Chicago. 
Whyte, K.P., Selinger, E., Caplan, A.L., \& Sadowski, J. (2012). Nudge, nudge or shove, shove - The right way for nudges to increase the supply of donated cadaver organs. American Journal of Bioethics 12(2), 32-39.

Zauberman, G. \& Lynch J.G. (2005). Resource slack and propensity to discount delayed investments of time versus money. Journal of Experimental Psychology 134, 23-37. 


\section{Figure 1.}

Organ donation under different scenarios and actual registration as donor, the Netherlands ${ }^{\mathrm{a}}$

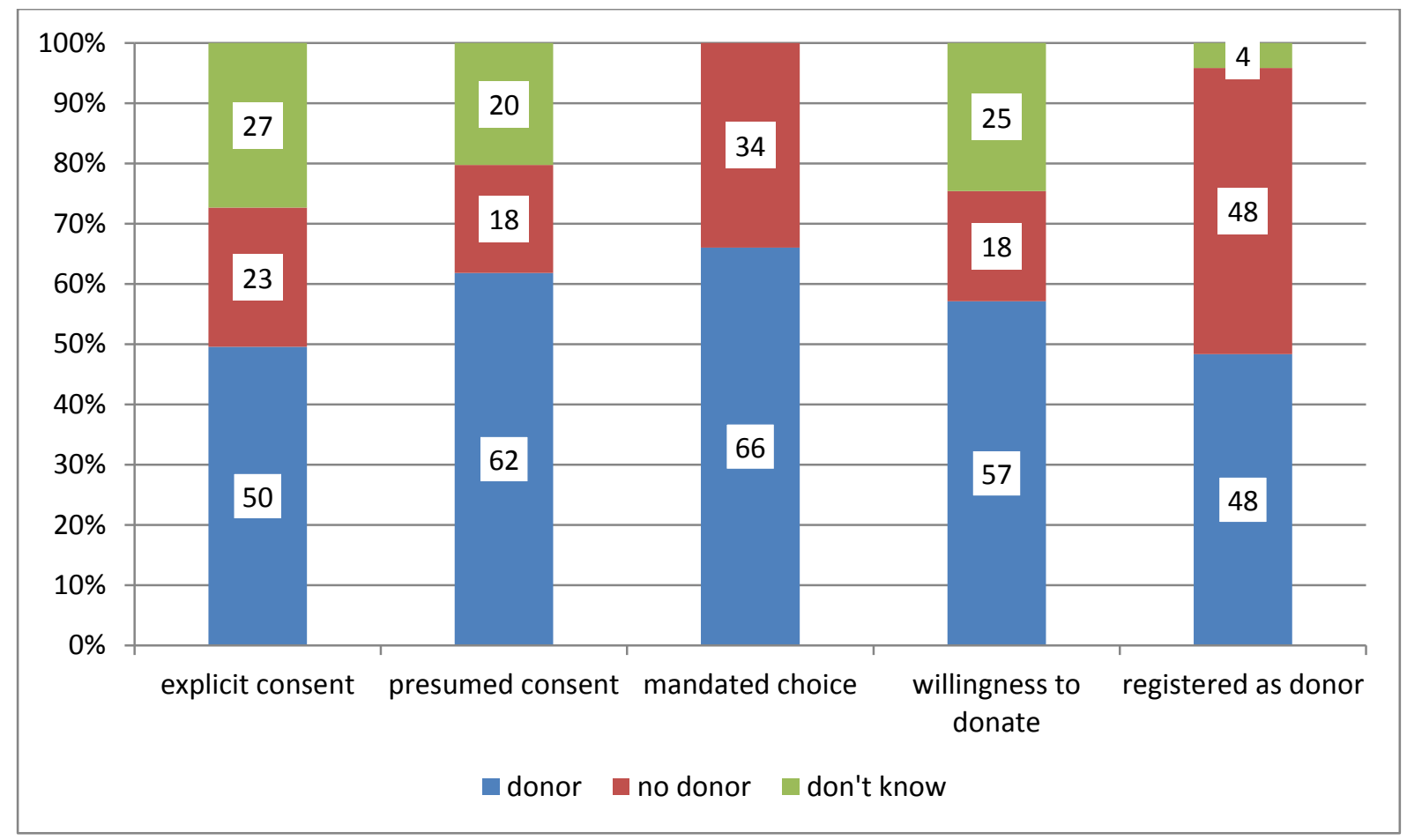

Source: NIDI (2011) 
Figure 2.

Confrontation of choice under various regimes versus actual choice (stated donor registration)

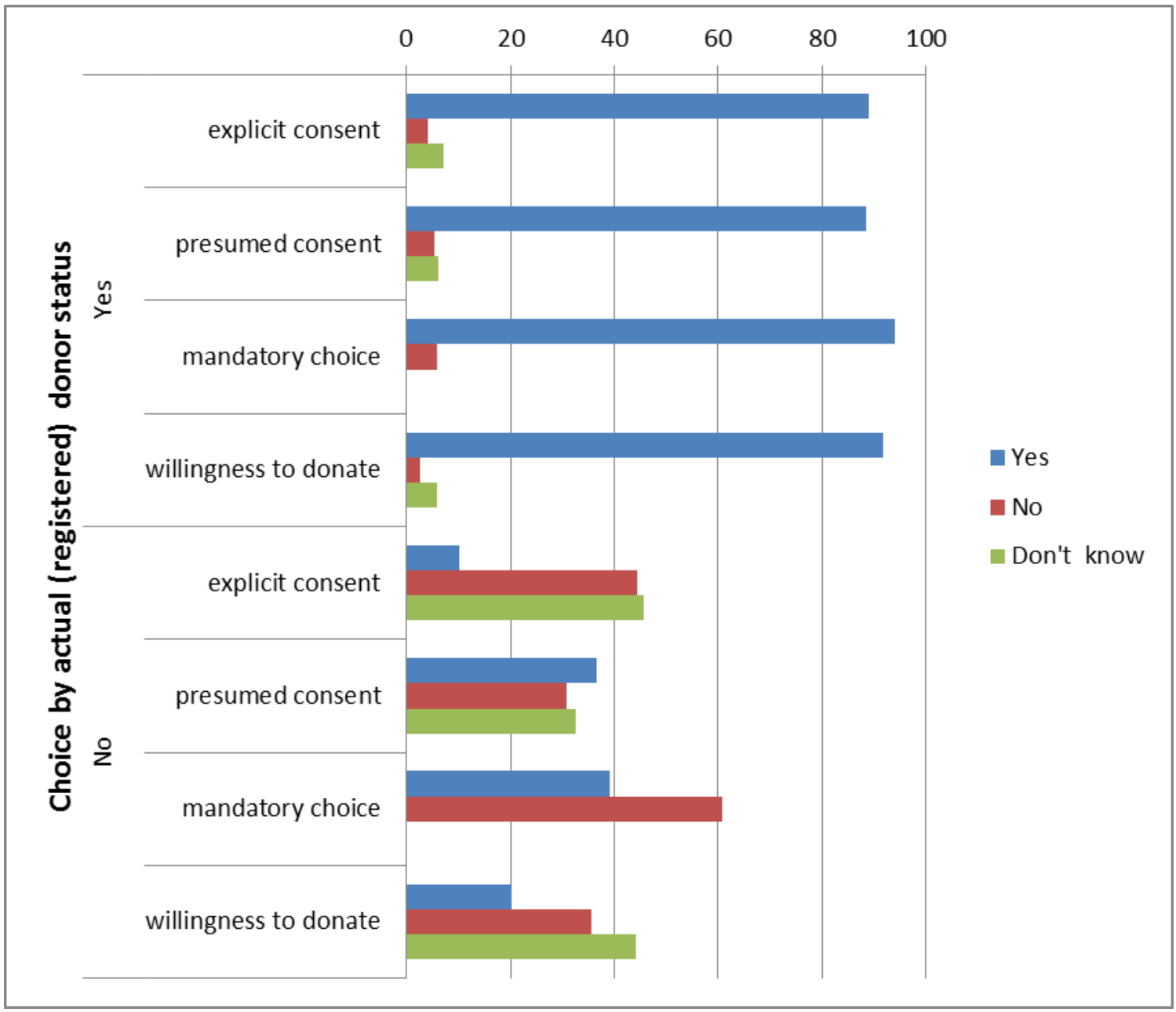

Source: NIDI (2011) 
Table 1

Explaining the choice to register as an organ donor under various defaults

\begin{tabular}{|c|c|c|}
\hline & \multicolumn{2}{|c|}{ Hypothetical choice (no and don't know = 0 ; yes $=1$ ) } \\
\hline \multirow[t]{2}{*}{ Independent variables: } & 1 & II \\
\hline & Odds ratio (t-value) & Odds ratio (t-value) \\
\hline Donor regime (A: explicit consent $=0)$ & - & - \\
\hline \multirow{2}{*}{ B: Presumed consent } & $1.69^{\star \star *}$ & $2.78^{\star \star \star}$ \\
\hline & $(3.97)$ & $(5.67)$ \\
\hline \multirow[t]{2}{*}{ C: Mandatory choice } & $2.03^{\star * *}$ & $3.53^{\star \star \star}$ \\
\hline & $(5.35)$ & $(7.30)$ \\
\hline \multirow[t]{2}{*}{ D: Neutral setting } & $1.36^{* * *}$ & $1.79^{\star \star \star}$ \\
\hline & $(2.48)$ & $(3.50)$ \\
\hline \multicolumn{3}{|l|}{ Stated as being registered donor $(\mathrm{no}=0)$} \\
\hline \multirow[t]{2}{*}{ Yes } & - & $30.29^{* \star *}$ \\
\hline & & $(29.84)$ \\
\hline \multirow[t]{2}{*}{ Don't know } & - & $3.54^{* \star *}$ \\
\hline & & $(5.33)$ \\
\hline \multirow[t]{2}{*}{ Sex $($ male $=0)$} & - & 1.11 \\
\hline & & $(0.92)$ \\
\hline \multirow[t]{2}{*}{ Age (years) } & - & 0.99 \\
\hline & & $(1.35)$ \\
\hline \multirow[t]{2}{*}{ Health status $^{a}$} & - & $1.15^{\star}$ \\
\hline & & $(1.77)$ \\
\hline Education $(\text { low }=0)^{b}$ & & - \\
\hline \multirow[t]{2}{*}{ Middle } & - & $1.48^{\star *}$ \\
\hline & & $(2.48)$ \\
\hline \multirow[t]{2}{*}{ Higher } & - & $1.52^{* \star *}$ \\
\hline & & $(2.99)$ \\
\hline Religion (none $=0$ ) & & - \\
\hline \multirow[t]{2}{*}{ (Roman) Catholic } & - & 0.81 \\
\hline & & $(1.49)$ \\
\hline \multirow[t]{2}{*}{ Protestant } & - & $0.73^{*}$ \\
\hline & & $(1.76)$ \\
\hline \multirow[t]{2}{*}{ Other religions } & - & $0.52^{\star *}$ \\
\hline & & $(2.38)$ \\
\hline Pseudo $\mathrm{R}^{2}$ & 0.01 & 0.36 \\
\hline
\end{tabular}

$\mathrm{N}=2,068 ; * \mathrm{p}<0.1 ; * * \mathrm{p}<0.05 ; * * * \mathrm{p}<0.01$, to take account of the possibility that observations may be correlated within households, the cluster option within Stata is used. The statistical method used is logit analysis. (a) Self-reported health is approximated by a scale from (1) very bad to (5) very good.

Source: NIDI (2011). 